\title{
Knowledge, Attitudes, and Practices Regarding Diabetes Mellitus Among University Students in Jeddah, Saudi Arabia
}

This article was published in the following Dove Press journal: Diabetes, Metabolic Syndrome and Obesity: Targets and Therapy

\section{Zohair J Gazzaz}

Department of Internal Medicine, Faculty of Medicine, Rabigh, King Abdulaziz University, Jeddah, Saudi Arabia
Correspondence: Zohair J Gazzaz

Department of Internal Medicine, Faculty of Medicine, Rabigh, King Abdulaziz University, Jeddah, Saudi Arabia

Tel + 966505664144

Email zjgazzaz@kau.edu.sa
Purpose: This study aimed to investigate knowledge, attitudes, and practices regarding diabetes mellitus (DM) among university students.

Material and Methods: This cross-sectional study was carried out at the Faculty of Medicine, Rabigh, King Abdulaziz University (KAU) Jeddah, Kingdom of Saudi Arabia (KSA), in 2018. All participants were the registered students at the foundation year in the branch of KAU, Rabigh. A questionnaire was developed that had questions related to knowledge, attitudes, and practices.

Results: A total of 1428 participants (770 [53.9\%] females and 658 [46.1\%] males) were included in the study. Surprisingly, there were 315 (22.1\%) students who had been diagnosed with hypertension or told by the healthcare professional that he/she has increased blood pressure, and 223 (15.6\%) had high blood sugar. There were 785 (55\%) participants who had one or more DM relative. Among our students, only $186(13 \%)$ had good knowledge scores, while $569(39.8 \%)$ and $673(47.1 \%)$ had moderate and poor knowledge scores, respectively. Interestingly, $1190(83.3 \%)$ participants had positive attitudes, while 238 (16.7\%) had negative attitudes. More than half of the participants, 844 (59.1\%), were practicing adequately for preventing DM. It was observed that females had significantly better general knowledge about DM, its risk factors, signs and symptoms, control and management, complications, and total knowledge scores. Our results showed that the female gender was associated with good knowledge and positive attitude and relatives diagnosed with DM were associated with good knowledge score. The participants who had DM relative and hypertension were more likely to have good attitudes and practices, respectively, in preventing DM. Conclusion: Our students' knowledge score was not up to the mark. Interestingly, participants had positive attitudes and practicing adequately for preventing DM. The female gender was associated with good knowledge scores and positive attitudes.

Keywords: diabetes mellitus, awareness, attitude, practice, students

\section{Introduction}

The youth are the future of a country and are considered dynamic human capital that plays a vital role in nation-building. If students adopt sedentary lifestyles and are inclined to fast food and irregular eating habits, then there is a lot of probability of suffering from being overweight, obese, and, consequently, type 2 diabetes mellitus (T2DM) at a young age. The incidence of T2DM has tremendously increased globally in the last 20-30 years. It is basically due to changes in people's lifestyle by introducing fast foods, carbonated and energy drinks, and reduced 
energy expenditure by manual hard work or regular exercise. ${ }^{1}$ International Diabetes Federation stated that people with diabetes is expected to increase from 171 million in 2000 to 578 million in 2030 globally. In July 2020, the number of people with diabetes is calculated to be almost 463 million worldwide. ${ }^{2}$

Saudi Arabia (SA) is an affluent society, ranking 2nd highest in the number of DM patients in the Arab world and 7th highest globally. Around 7 million Saudi Arabian citizens are suffering from DM, mostly the T2DM. ${ }^{3}$ Some recent studies reported the incidence of DM around 23.4\% in the SA population, the incidence being higher in males than in females. ${ }^{4}$ Additionally, SA has been ranked among high-risk nations regarding overweight and obesity, which is a great challenge for the country's public health. ${ }^{5}$ There is a strong relationship between obesity, DM, hypertension, and many other comorbidities. According to a study, over 20,000 annual obesity-related deaths occur in KSA, and a high prevalence of obesity was found in children and adolescents. $^{6}$

The level of awareness and knowledge regarding the disease among the population helps a community manage it properly both on the prevention and management front. It is very important to target the sections of society who are or would be involved in the care of diseased persons because if we succeed in creating good awareness and positive attitudes towards the difficulties and miseries of the patient in our future health care professionals, then we can expect positive trends both in planning and management side. $^{7}$

Dealing with chronic diseases like DM, various aspects need proper attention like health knowledge, the importance of regular exercise, taking a balanced diet and avoiding junk foods and above all creating a healthy atmosphere in the society so that each individual realize ones' responsibility to keep himself and his family members in optimal healthy state. ${ }^{8}$

The prevalence of DM is common in SA, so there is a need to explore our young students' awareness of DM. So that policymakers can devise policies to educate the young generation. We aimed to investigate knowledge, attitudes, and practices regarding DM among university students.

\section{Materials and Methods}

This prospective study was carried out in the Faculty of Medicine, Rabigh, King Abdulaziz University Jeddah, in 2018. Ethical approval was obtained from the college
Research Ethics Committee (REC), Faculty of Medicine, Rabigh. For this analysis, the measured sample size was 382 with absolute error (5\%) and confidence levels of $95 \%$. Fifteen hundred students were invited to participate in this survey, and 1428 participants returned completed questionnaires with a response rate of $95 \%$. The participants were selected by convenience sampling technique. All participants written consent was obtained before the commencement of the study and they were informed about the purpose of the study. A questionnaire was constructed in the English language with several sections: a) demographic, b) knowledge, c) attitude d) practice questions.

All participants were the registered students at the foundation year in the branch of KAU in Rabigh. The Rabigh city is located at the Red sea's seashore, $160 \mathrm{Km}$ away from KAU's main campus in Jeddah city. ${ }^{9}$ In the $\mathrm{KAU}$, before admitting students in the different faculties of the university one-year preparatory course is offered, in which English, Physics, Chemistry, Biology is taught. After completing that year, a test is conducted, and then students are placed choice-cum-merit bases in the different faculties.

A questionnaire was developed that had 43, 11 and 10 questions related to knowledge, attitudes, and practices, respectively. The two senior faculty members checked the questionnaire's validity and comprehension, and it was revised according to their suggestions. A pilot study was conducted on 35 students to check the questionnaire's understanding and responses further, and its Cronbach's alpha was 0.75 . The results of the pilot study were not included in the final analysis.

\footnotetext{
The scoring of the knowledge questions was done as $\leq 50 \%$ score $=$ poor knowledge $(1-21$ score $), 50 \%-75 \%$ score $=$ moderate knowledge $(22-33$ score $),>75 \%$ score $=$ good knowledge (34-43). For the attitude scoring was done as correct answer $=1$ score, incorrect $(\mathrm{No})=$ minus score, unsure $=0$ score. Plus score was considered positive, while 0 or minus score was considered negative. The practice questions were coded as correct (yes) answer $=1$ score, incorrect $(\mathrm{No})=$ zero score, unsure $=0$ score and $>50 \%$ score was considered adequate.
}

\section{Statistical Analysis}

We analyzed data on SPSS-26. The frequency and percentages were computed for different variables. Chi-square test was used to find out the comparison between different variables. Association of knowledge, attitudes, and practice scores regarding DM with different variables was 
Table I Study Participants General Characteristics

\begin{tabular}{|l|l|l|}
\hline Variables & Frequency & Percentage \\
\hline $\begin{array}{l}\text { Gender } \\
\text { Male }\end{array}$ & 658 & \\
Female & 770 & 46.1 \\
\hline Hypertension & & 53.9 \\
No & 1113 & \\
Yes & 315 & 77.9 \\
\hline High blood sugar & & 22.1 \\
No & 1205 & \\
Yes & 223 & 84.4 \\
\hline Relative with DM & & 15.6 \\
No & 643 & \\
Yes & 785 & 45 \\
\hline Relationship with diabetic relative & & 55 \\
Parent & 275 & \\
Grand parent & 223 & 19.3 \\
Brother & 77 & 5.4 \\
First cousin & 76 & 5.3 \\
Aunt/Uncle & 47 & 3.3 \\
Others & 87 & 6 \\
\hline
\end{tabular}

calculated using binary logistic regression analysis. The p-values of less than 0.05 were taken significant.

\section{Results}

A total of 1478 students filled the questionnaire, but after removing fifty incomplete responses, 1428 participants (770 [53.9\%] females and 658 [46.1\%] males) were included in the study. All participants were the students of the foundation year. There were 315 (22.1\%) students who had been diagnosed with hypertension or told by the healthcare professional that he/she has hypertension, and 223 (15.6\%) had high blood sugar. There were $785(55 \%)$ participants who had one or more DM relatives (Table 1). Among our students, only 186 (13\%) had good knowledge scores, while 569 (39.8\%) and 673 (47.1\%) had moderate and poor knowledge scores, respectively. Interestingly, 1190 (83.3) participants had positive scores indicated positive attitudes, while 238 (16.7\%) had negative or zero scores indicated negative attitudes. More than half of the participants, $844(59.1 \%)$, were practicing adequately, whereas $41 \%$ of the participants were carefree, and their practices were inadequate for preventing DM (Figure 1).

We analyzed the gender-wise comparison of students' knowledge of different subcategories regarding the knowledge domain. It was observed that females had significantly better knowledge in DM general knowledge, risk factors, signs and symptoms, control and management, complications, and total knowledge scores (Table 2). Study participants' knowledge scores and attitudes showed that females had better knowledge scores and positive attitudes compared to males $(p=<.001$, and $\mathrm{p}=0.009$ ), while no difference was found in practice scores $(\mathrm{p}=0.515)$. Students who had DM close relative had good knowledge scores $(p=<.001)$, and more positive attitudes $(p<0.001)$, and adequate preventive practices $(p=<.001)$ than those who had no relative with DM. The knowledge scores and attitudes of students without hypertension were better compared to hypertensive $(p=<.001, p=0.032$, respectively), while no difference was found in preventive practices $(\mathrm{p}=0.066)$. The knowledge scores and attitudes among students without high blood sugar were better $(\mathrm{p}=0.031, \mathrm{p}=0.034$, respectively $)$ than with high blood sugar (Table 3).

Linear regressions analysis showed that the female gender, high blood sugar level, and relatives diagnosed with DM were associated with good knowledge scores (Table 4). In logistic regression analysis, the odds ratio $(\mathrm{OR}=1.355)$ indicated that females were $35 \%$ more likely to have positive attitudes than males. Participants who had relatives with DM and the OR (0.53) indicated that they were $47 \%$ more likely to have positive attitudes. The logistic regression of different variables with practice showed that the participants who had hypertension $(\mathrm{OR}=1.31)$ indicated $31 \%$ more likely to have good practice in preventing DM. In comparison, those who had relatives with $\mathrm{DM}(\mathrm{OR}=0.66)$ were $36 \%$ less likely to have good practices in preventing DM (Table 5).

\section{Discussion}

All participants in our study were the students of the foundation year. Our results showed that surprisingly, $22.1 \%$ of students had been diagnosed with hypertension or told by the healthcare professional that he/she has raised blood pressure, and 15.6\% had high blood sugar levels one or more times. More than half (55\%) of students had one or more DM relative. Among our students, almost half of the students had poor knowledge scores. Importantly, four out of five participants had positive attitudes, and three out of five students were practicing adequately for preventing DM. A previous study carried out five-years back at the KAU revealed a $7.5 \%$ incidence of hypertension and $48.4 \%$ overweight and obesity among university students. ${ }^{10}$ Another Saudi study reported the association 
$100 \%$

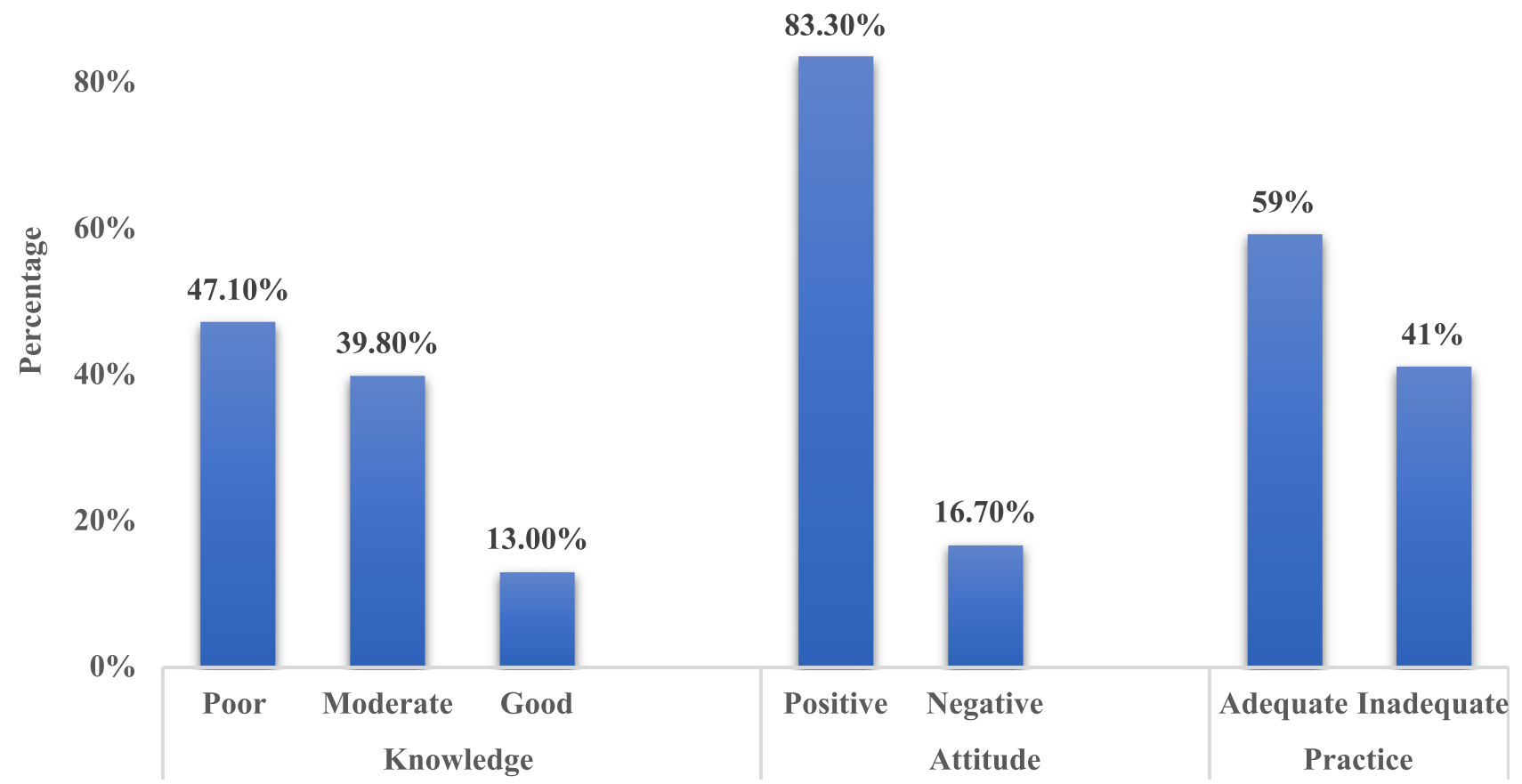

Particpants knowledge, attitude and practice scores

Figure I Study participants knowledge, attitudes, practices regarding DM.

of hypertension, DM, and obesity, and around $70 \%$ of their study participants, aged 15 or above, were found to be obese. $^{11}$

The overall incidence of obesity in Saudi Arabia is $35.4 \%$, which is much higher than that of neighboring Arab countries. ${ }^{12}$ Another previous study from our university has reported irregular dietary patterns and most university students' sedentary lifestyles. They also reported $58.6 \%$ of the university students were overweight and obese. ${ }^{13} \mathrm{~A}$ recent study mentioned that DM could be effectively managed and controlled by early screening and abandoning sedentary routine. Adopting healthy lifestyles can be very useful in avoiding all the complications of this avertable disease. ${ }^{14}$

\section{Knowledge}

Essential knowledge regarding the risk factors and preventive aspects of a particular disease in a group or community is mandatory for control and proper management and to control the further spread of this disease in a given setup. As a group, our participants require a lot of awareness of this aspect as we observed that a small percentage (13\%) of our study cohort attained good knowledge scores. In contrast, almost half of the participants scored poorly regarding the basic knowledge of DM. In a study, Baig et al (2015) revealed similar trends of having poor knowledge regarding CVD in KAU students. ${ }^{10}$ In a recent survey, Alqahtani et al (2020) in Riyadh, KSA, revealed better knowledge scores among the adult population regarding DM. ${ }^{15}$ Alenazi et al (2020) mentioned relatively better $(62.6 \%)$ knowledge scores in young school children regarding DM. ${ }^{16}$ Quite interestingly, it was observed that females had significantly better knowledge regarding DM general knowledge, risk factors, signs and symptoms, control and management, complications, and total knowledge scores. A Chinese study reported inadequate knowledge of diabetes and its related factors among college students. About less than half of the respondents have correct knowledge about the start of the DM, impacts of physical inactivity, and DM complications. ${ }^{17}$

A study reported knowledge about DM, its complications, and management in DM patients. ${ }^{7}$ They revealed relatively poor knowledge among patients. ${ }^{7}$ Another study from KSA regarding awareness about DM's risk factors reported that almost $50 \%$ of the study participants did not have up to the mark knowledge regarding DM. In contrast to our results, females' knowledge was not better. ${ }^{18,19}$ A study in the United Arab Emirates reported low DMrelated knowledge among university students. ${ }^{20}$ Similarly, in Muscat, only one-quarter of the high school students 
Table 2 Gender-Wise Comparison of Students' Knowledge in Different Subcategories of Knowledge Domain

\begin{tabular}{|c|c|c|c|c|}
\hline Variables & Gender & $\mathbf{N}$ & Mean (SD) & p-value \\
\hline DM General Knowledge & $\begin{array}{l}\text { Female } \\
\text { Male }\end{array}$ & $\begin{array}{l}741 \\
687\end{array}$ & $\begin{array}{l}4.91(2.34) \\
4.62(2.14)\end{array}$ & $0.016^{*}$ \\
\hline DM Risk factor knowledge & $\begin{array}{l}\text { Female } \\
\text { Male }\end{array}$ & $\begin{array}{l}741 \\
687\end{array}$ & $\begin{array}{l}4.14(2.10) \\
3.65(1.74)\end{array}$ & $<0.00 I^{*}$ \\
\hline DM signs symptoms knowledge & $\begin{array}{l}\text { Female } \\
\text { Male }\end{array}$ & $\begin{array}{l}741 \\
687\end{array}$ & $\begin{array}{l}4.33(2.28) \\
3.88(2.08)\end{array}$ & $<0.00 I^{*}$ \\
\hline DM precaution Knowledge & $\begin{array}{l}\text { Female } \\
\text { Male }\end{array}$ & $\begin{array}{l}741 \\
687\end{array}$ & $\begin{array}{l}2.53(1.36) \\
2.31(1.27)\end{array}$ & $0.002 *$ \\
\hline DM control and management Knowledge & $\begin{array}{l}\text { Female } \\
\text { Male }\end{array}$ & $\begin{array}{l}741 \\
687\end{array}$ & $\begin{array}{l}3.93(2.07) \\
3.48(1.90)\end{array}$ & $<0.00 I^{*}$ \\
\hline DM monitoring knowledge & $\begin{array}{l}\text { Female } \\
\text { Male }\end{array}$ & $\begin{array}{l}741 \\
687\end{array}$ & $\begin{array}{l}\text { I.I8(I.05) } \\
1.08(0.94)\end{array}$ & 0.067 \\
\hline DM complications knowledge & $\begin{array}{l}\text { Female } \\
\text { Male }\end{array}$ & $\begin{array}{l}741 \\
687\end{array}$ & $\begin{array}{l}3.29(1.33) \\
2.91(1.24)\end{array}$ & $<0.00 I^{*}$ \\
\hline DM total Knowledge Score & $\begin{array}{l}\text { Female } \\
\text { Male }\end{array}$ & $\begin{array}{l}741 \\
687\end{array}$ & $\begin{array}{l}24.34(9.58) \\
21.95(8.36)\end{array}$ & $<0.00 I^{*}$ \\
\hline
\end{tabular}

Note: ${ }^{p}<0.05$ was considered significant.

Table 3 Comparison of Knowledge, Attitudes, and Practices Scores According to Different Variables

\begin{tabular}{|c|c|c|c|c|c|c|c|c|}
\hline \multicolumn{2}{|l|}{ Variables } & \multicolumn{3}{|c|}{ Knowledge } & \multicolumn{2}{|l|}{ Attitude } & \multicolumn{2}{|l|}{ Practice } \\
\hline & & \multirow{3}{*}{$\begin{array}{l}\text { Poor } \\
293(43.5) \\
380(56.5\end{array}$} & \multirow{3}{*}{$\begin{array}{l}\text { Moderate } \\
315(55.4) \\
254(46.6)\end{array}$} & \multirow{3}{*}{$\begin{array}{l}\text { Good } \\
133(7 \mid .5) \\
53(28.5)\end{array}$} & \multirow{3}{*}{$\begin{array}{l}\text { Negative } \\
105(44.1) \\
133(55.9)\end{array}$} & \multirow{3}{*}{$\begin{array}{l}\text { Positive } \\
636(53.4) \\
554(46.6)\end{array}$} & \multirow{3}{*}{$\begin{array}{l}\text { Inadequate } \\
297(50.9) \\
287(49.1)\end{array}$} & \multirow{3}{*}{$\begin{array}{l}\text { Adequate } \\
444(52.6) \\
400(47.4)\end{array}$} \\
\hline Gender & Female & & & & & & & \\
\hline & Male & & & & & & & \\
\hline $\mathrm{p}$-value & \multicolumn{4}{|l|}{$<0.001 *$} & \multicolumn{2}{|l|}{$0.009 *$} & \multicolumn{2}{|l|}{0.515} \\
\hline \multirow[t]{2}{*}{ Relative with DM } & No & $380(56.5)$ & 193(33.9) & $70(37.6)$ & $143(60)$ & $500(42)$ & $300(51.4$ & $343(40.6$ \\
\hline & Yes & $293(43.5$ & $376(66.1)$ & $116(62.4)$ & 95 (39.9) & $690(58)$ & $284(48.6)$ & $50 \mathrm{I}(59.4)$ \\
\hline $\mathrm{p}$-value & \multicolumn{4}{|l|}{$<0.00 I^{*}$} & \multicolumn{2}{|l|}{$<0.001 *$} & \multicolumn{2}{|l|}{$<0.001 *$} \\
\hline \multirow[t]{2}{*}{ High blood sugar } & No & $550(81.7$ & $495(87)$ & $160(86)$ & $190(79.8)$ & $1015(85.3)$ & $492(84.2$ & $713(84.5$ \\
\hline & Yes & $123(18.3)$ & $74(13)$ & $26(14)$ & $48(20.2)$ & $175(14.7)$ & $92(15.8)$ & $13 \mid(15.5$ \\
\hline $\mathrm{p}$-value & \multicolumn{4}{|l|}{$0.031^{*}$} & \multicolumn{2}{|l|}{0.034} & \multicolumn{2}{|l|}{0.905} \\
\hline \multirow[t]{2}{*}{ Hypertension } & No & $482(71.6$ & $479(84.2)$ & $152(81.7)$ & I73(72.7) & $940(79)$ & $44 \mid(75.5$ & 672(79.6) \\
\hline & Yes & $191(28.4)$ & $90(15.8)$ & $34(18.3)$ & $65(27)$ & $250(21)$ & $143(24.5)$ & I $72(20.4)$ \\
\hline $\mathrm{p}$-value & \multicolumn{4}{|l|}{$<0.00 I^{*}$} & \multicolumn{2}{|l|}{$0.032 *$} & \multicolumn{2}{|l|}{0.066} \\
\hline
\end{tabular}

Note: ${ }^{p}<0.05$ was considered significant.

had adequate knowledge regarding $\mathrm{DM} .^{21} \mathrm{~A}$ study from Uganda reported good knowledge score among university students. The majority of the respondents had adequate knowledge about the risk factors and symptoms of DM. ${ }^{22}$

Exploration of knowledge regarding DM was the main subject of a couple of other studies and guide the health care planning in a better way. ${ }^{23-25}$ The participants with a close relative with DM exhibited better knowledge scores than those with no history of DM in the family. In a Chinese study, those students who had DM relatives in the family had significantly higher knowledge, and medical students and females had better knowledge than non-medical students and male students. ${ }^{17}$ 
Table 4 Association of Knowledge Scores with Different Variables (Linear Regression Analysis)

\begin{tabular}{|c|c|c|c|c|c|c|c|c|}
\hline \multirow{2}{*}{\multicolumn{2}{|c|}{ Model }} & \multicolumn{2}{|c|}{$\begin{array}{l}\text { Unstandardized } \\
\text { Coefficients }\end{array}$} & \multirow{2}{*}{$\begin{array}{l}\text { Standardized Coefficients } \\
\text { Beta }\end{array}$} & \multirow[t]{2}{*}{$\mathbf{t}$} & \multirow[t]{2}{*}{ Sig. } & \multicolumn{2}{|c|}{$\begin{array}{l}95.0 \% \text { Confidence Interval for } \\
\text { B }\end{array}$} \\
\hline & & B & Std. Error & & & & Lower Bound & Upper Bound \\
\hline \multirow[t]{5}{*}{1} & (Constant) & 15.846 & 0.786 & & 20.152 & $<0.00 I^{*}$ & 14.303 & 17.388 \\
\hline & Female & 2.185 & 0.435 & 0.120 & 5.024 & $<0.00 I^{*}$ & 1.332 & 3.039 \\
\hline & Hypertension & -.093 & 0.567 & -.004 & -.164 & 0.870 & -1.205 & 1.020 \\
\hline & High blood sugar & 2.317 & 0.643 & 0.093 & 3.602 & $<0.00 I^{*}$ & 1.055 & 3.579 \\
\hline & Relative with diabetes & 3.336 & 0.435 & 0.183 & 7.670 & $<0.00 I^{*}$ & 2.483 & 4.190 \\
\hline
\end{tabular}

Note: ${ }^{*} \mathrm{p}<0.05$ was considered significant.

Table 5 Association of Attitudes and Practices Scores with Different Variables (Binary Logistic Regression Analysis)

\begin{tabular}{|l|l|l|l|l|l|l|}
\hline \multirow{2}{*}{ Variables } & \multicolumn{2}{l|}{ Attitudes } & \multicolumn{2}{l|}{ Practices } \\
\cline { 2 - 7 } & B & P-value & OR & B & P-value \\
\hline Male & Reference & & & & \\
Female & 0.304 & $0.043^{*}$ & 1.355 & $0.08 \mathrm{I}$ & 0.466 & \\
Hypertension & 0.001 & 0.996 & 1.001 & 0.275 & $<0.049^{*}$ & 1.084 \\
High blood sugar & 0.000 & 0.998 & 1.000 & -.127 & 0.431 & 1.316 \\
Relative with diabetes & 0.620 & $<0.00 I^{*}$ & 0.538 & 0.434 & $<0.00 I^{*}$ & 0.881 \\
Constant & 1.390 & $<0.00 I^{*}$ & 4.015 & 0.962 & $<0.027^{*}$ \\
\hline
\end{tabular}

Note: ${ }^{*} p<0.05$ was considered significant.

Unexpectedly, the participants without hypertension were well informed compared to the hypertensive ones $(p \leq .001)$. In contrast to our results, a study mentioned that hypertensive patients had better knowledge of the disease than non-hypertensives. ${ }^{26}$

It is suggested that the university administration arrange some regular educational lectures regarding DM awareness to improve students' knowledge of this silent and preventable disease with many comorbidities, and that had a lot of burden on the country's healthcare system.

\section{Attitudes and Practices}

Attitude refers to individuals' feelings towards a particular subject if they have preconceived ideas about it and how they demonstrate their knowledge towards controlling that specific condition. In contrast, by practice, one refers to how the knowledge and attitudes are demonstrated in a practical approach to control a condition or a disease state. ${ }^{27}$ The majority of our participants showed positive attitudes towards the preventive aspects of DM. Females demonstrated a relatively more positive attitude as compared to male counterparts. A small percentage of the students showed negative attitudes and practices towards preventive efforts against DM. It is unpredictably surprising that the knowledge score was not good, but the attitudes and practices were more positive and adequate, respectively. Two recent studies in KSA mentioned the easy-going or rather a careless attitude of young males and females, showing negative attitudes towards the preventive aspects of DM. ${ }^{15,26}$ The majority of our study cohort mentioned practicing preventive measures against DM. Both genders were equally involved, so no statistical difference in males and females' preventive practice scores was noted. Students with a family member having diabetes showed adequate preventive practices than the other group ( $p<0.001$ ). Similarly, two other studies mentioned positive practices among the closely related individuals of DM patients. ${ }^{27,28}$

A significant association of good knowledge scores was observed with female gender, high blood sugar levels, and students who had DM relatives. The female gender was also associated with a positive attitude. The participants who had hypertension were more likely to have good practices in preventing DM, while those with DM relatives were less likely to have good practices in preventing DM. A recent study reported that gender and family history of DM and education were the predictor of knowledge, attitudes, 
practices for DM. ${ }^{29}$ Concerning attitudes and practices, our results are similar to a study, but higher knowledge scores were reported among students in that study. ${ }^{30}$

More awareness regarding any disease could decrease the prevalence of the disease. This is an alarming issue that a notable number of young students had hypertension and hyperglycemia, and they were not taking care of these issues. Their non-serious attitude may put them in jeopardy, and if they did not change their behavior and lifestyle, they would have to face the grave consequences of this dangerous problem. The educational institutes should run continuous awareness campaigns via university websites, mobile applications and regularly arrange seminars and guest lectures. They should display panaflex banners, billboards, and hoardings, in the university as an awareness campaign regarding DM. They should also publish awareness leaflets for the students.

$\mathrm{DM}$ is a comparatively silent disease but has several dangerous long-term complications. The crucial aftereffects of this problem are not only on the individual's health but also on the country's economic status and the healthcare system. The younger generation is the backbone of any country. Students life is the formative period for an individual. They should not be the burden but the powerhouse for the country's growth. Therefore, it needs special attention from the policymakers to make them aware of their role in society and provide them such a conducive environment that improves their learning skills, leadership qualities, and mental and physical health.

\section{Limitations}

This survey could not check the study participants' BMI, $\mathrm{BP}$, and blood sugar levels. There was a need to explore the incidence of overweight and obesity in our study participants. Another drawback of such questionnaire studies is that participants usually opt for the perfect responses instead of the actual answer that reflects their actual knowledge, attitudes, and practices.

\section{Conclusions}

Our participants' good knowledge score was not up to the mark. Interestingly, participants had positive attitudes and practicing adequately for preventing DM. The female gender was associated with good knowledge scores in multiple subcategories and positive attitudes. We suggest that community awareness campaigns should be initiated to improve young people's knowledge and attitude regarding obesity, DM, and related comorbidities.

\section{Acknowledgments}

The author would like to thank, for their technical support, the members of Bait Al-Khibra (House of Expertise) at King Abdulaziz University, Jeddah, Saudi Arabia, especially the Scientific Advisor Professor Hamed Habib (former Dean Faculty of Medicine, Rabigh). The author also wish to thanks the Deanship of Scientific Research (DSR), King Abdulaziz University, Jeddah, Saudi Arabia, for their support for the publication of this study.

\section{Disclosure}

The author reports no conflicts of interest in this work.

\section{References}

1. Hoda M, Hemaiswarya S, Doble M. Diabetes: Its Implications, Diagnosis, Treatment, and Management. In: Role of Phenolic Phytochemicals in Diabetes Management. Singapore: Springer; 2019:1-12.

2. Williams R, Karuranga S, Malanda B, et al. Global and regional estimates and projections of diabetes-related health expenditure: results from the international diabetes federation diabetes Atlas. Diabetes Res Clin Pract. 2020;162:108072. doi:10.1016/j. diabres.2020.108072

3. Al Dawish MA, Alwin Robert AA, Braham R, et al. Diabetes mellitus in Saudi Arabia: a review of the recent literature. Curr Diabetes Rev. 2016;12(4):359-368. doi:10.2174/1573399811666150724095130

4. Almetwazi M, Alwhaibi M, Balkhi B, et al. Factors associated with glycemic control in type 2 diabetic patients in Saudi Arabia. Saudi Pharm J. 2019;27(3):384-388. doi:10.1016/j.jsps.2018.12.007

5. Balgoon MJ, Al-Zahrani MH, Alkhattabi NA, et al. The correlation between obesity and metabolic syndrome in young female university students in the Kingdom of Saudi Arabia. Diabet Metab Synd. 2019;13(4):2399-2402. doi:10.1016/j.dsx.2019.06.015

6. Al-Raddadi R, Bahijri SM, Jambi HA, et al. The prevalence of obesity and overweight, associated demographic and lifestyle factors, and health status in the adult population of Jeddah, Saudi Arabia. Ther Adv Chronic Dis. 2019;10:204062231987899. doi:10.1177/2040622319878997

7. Ahmed IB, Binnwejim MS, Alnahas TM, et al. Level of diabetic patients' knowledge of diabetes mellitus, its complications and management. Arch Pharm Pract. 2019;39:981-989. doi:10.15537/ smj.2018.10.22938

8. American Diabetes Association. 5. Lifestyle management: standards of medical care in diabetes-2019. Diabetes Care. 2019;42 (Supplement 1):S46-60. doi:10.2337/dc19-S005.

9. Imran M, Shamim MS, Baig M, et al. Tale of two cities: comparison of educational environment of two colleges (Jeddah and Rabigh) affiliated with one university. J Pak Med Assoc. 2016;66:316-319.

10. Baig M, Gazzaz ZJ, Gari MA, et al. prevalence of obesity and hypertension among University students' and their knowledge and attitude towards risk factors of Cardiovascular Disease (CVD) in Jeddah, Saudi Arabia. Pak J Med Sci. 2015;31:816-820. doi:10.12669/pjms.314.7953

11. Al-Sumaih I, Johnston B, Donnelly $\mathrm{M}$, et al. The relationship between obesity, diabetes, hypertension and vitamin D deficiency among Saudi Arabians aged 15 and over: results from the Saudi health interview survey. BMC Endocr Disord. 2020;81:20. doi:10.1186/s12902-020-00562-z

12. World Health Organization. Global Health Observatory (GHO) data. Overweight and obesity; 2016. Available from: https://www.who.int/ gho/ncd/risk_factors/overweight_obesity/obesity_adults/en/. Accessed May 15, 2019. 
13. Khabaz MN, Bakarman MA, Baig M, et al. Dietary habits, lifestyle pattern and obesity among young Saudi university students. J Pak Med Assoc. 2017;67:1541-1546.

14. Gazzaz ZJ, Iftikhar R, Jameel T, et al. Association of dyslipidemia and comorbidities with risk factors among diabetic patients: a retrospective analysis. Diabetes Metab Syndr Obes. 2020;13:935-941. doi:10.2147/DMSO.S235546

15. Alqahtani M, Almutairi FE, Albasseet AO, et al. Knowledge, attitude, and practice of diabetes mellitus among the saudi population in Riyadh, Saudi Arabia: a quantitative study. Cureus. 2020;12:e6601. doi:10.7759/cureus.6601

16. Alenazi MA, Alenezi SH, Alhablani MN, et al. Knowledge and awareness of diabetes mellitus disease among high school students in King Abdulaziz Military City, Tabuk, Saudi Arabia. Open Access Maced J Med Sci. 2020;8(E):91-97. doi:10.3889/oamjms.2020.4194

17. Xu Y, Zhang D, Liu K, et al. Self-reported knowledge on diabetes and its related factors among Chinese college students: a cross-sectional study. BMJ Open. 2016;6(9):e011963. doi:10.1136/ bmjopen-2016011963

18. Ahmed IB, Alateeq FA, Alharbi SH, et al. Awareness and knowledge towards type 2 diabetes mellitus risk factors in Northern Saudi Arabia. Int J Med Res Health Sci. 2018;7:33-40. doi:10.15537/ smj.2018.10.22938

19. Wadaani FA. The knowledge attitude and practice regarding diabetes and diabetic retinopathy among the final year medical students of King Faisal University Medical College of Al Hasa region of Saudi Arabia: a cross sectional survey. Niger J Clin Pract. 2013;16 (2):164-168. doi:10.4103/1119-3077.110133

20. Khan N, Gomathi KG, Shehnaz SI, et al. Diabetes mellitus-related knowledge among university students in Ajman, United Arab Emirates. Sultan Qaboos Univ Med J. 2012;12(3):306-314. doi:10.12816/0003144

21. Al-Mahrooqi B, Al-Hadhrami R, Al-Amri A, et al. Self-reported knowledge of diabetes among high school students in Al-Amerat and Quriyat, Muscat Governate, Oman. Sultan Qaboos Univ Med J. 2013;13(3):392-398. doi:10.12816/0003261
22. Kharono B, Nabisere R, Persis NK, et al. Knowledge, attitudes, and perceived risks related to diabetes mellitus among university students in Uganda: a cross-sectional study. East Afr Health Res J. 2017;1 (2):105-112. doi:10.24248/eahrj.v1i2.556

23. Abdulrahman M, Husain ZS, Abdouli KA, et al. Association between knowledge, awareness, and practice of patients with type 2 diabetes with socio-economic status, adherence to medication and disease complications. Diabetes Res Clin Pract. 2020;163:108124. doi:10.1016/j.diabres.2020.108124

24. Mercado E. Level of awareness, adherence to diet, self-monitoring and medication regimen among diabetic patients: a basis for improving diabetes specialty clinic services. $J$ Health Med Inform. 2019;10:2.

25. Alanazi FK, Alotaibi JS, Paliadelis P, et al. Knowledge and awareness of diabetes mellitus and its risk factors in Saudi Arabia. Saudi Med J. 2018;39(10):981-989. doi:10.15537/smj.2018.10.22938

26. Nisar S, Mazhar T, Arif I, Rehman FU. Knowledge and attitude of middle-age population towards predisposing factors of hypertension. J Rawalp Med Coll. 2019;23(S-1):45-49.

27. Asmelash D, Abdu N, Tefera S, et al. Knowledge, attitude, and practice towards glycemic control and its associated factors among diabetes mellitus patients. $J$ Diabetes Res. 2019;2019:1-9. doi:10.1155/2019/2593684

28. Alsous M, Abdel Jalil M, Odeh M, et al. Public knowledge, attitudes and practices toward diabetes mellitus: a cross-sectional study from Jordan. PLoS One. 2019:14. doi:10.1371/journal.pone.0214479.

29. Alsunni AA, Albaker WI, Almansour AH, et al. Knowledge, attitude and practice regarding ramadan fasting and related determinants in patients with type 2 diabetes at a Saudi Diabetes Clinic. Diabetes Metab Syndr Obes. 2020;13:151. doi:10.2147/DMSO.S241496

30. Mohammed AA, Al-Aaragi AN, Merzah MA. Knowledge, attitude, and practice regarding diabetic mellitus among a sample of students at technical institute of Karbala. Med J Babylon. 2018;15:164-168.

\section{Publish your work in this journal}

Diabetes, Metabolic Syndrome and Obesity: Targets and Therapy is an international, peer-reviewed open-access journal committed to the rapid publication of the latest laboratory and clinical findings in the fields of diabetes, metabolic syndrome and obesity research. Original research, review, case reports, hypothesis formation, expert opinion and commentaries are all considered for publication. The manuscript management system is completely online and includes a very quick and fair peer-review system, which is all easy to use. Visit http://www.dovepress.com/testimonials.php to read real quotes from published authors.

Submit your manuscript here: https://www.dovepress.com/diabetes-metabolic-syndrome-and-obesity-targets-and-therapy-journal 